\author{
Massimiliano Vignolo* \\ University of Genoa
}

\title{
CONTEXTUALISM, PRAGMATICS AND DEFINITE DESCRIPTIONS
}

\begin{abstract}
Very few philosophers and linguists doubt that definite descriptions have attributive uses and referential uses. The point of disagreement concerns whether the difference in uses is grounded on a difference in meaning. The Ambiguity Theory holds while the Implicature Theory denies that definite descriptions are ambiguous expressions, having an attributive meaning and a referential meaning. Contextualists have attempted to steer between the Ambiguity Theory and the Implicature Theory. I claim that the early contextualist account provided by Recanati and Bezuidehnout based on the idea that definite descriptions are semantically underdetermined and in need of a completion from the contextually available information through an optional top-down pragmatic process suffers from an explanatory gap.
\end{abstract}

\section{Keywords}

contextualism, definite descriptions, referential, attributive, modulation, saturation

\section{Introduction}

Very few philosophers and linguists doubt that definite descriptions have attributive uses and referential uses. The point of disagreement concerns whether the difference in uses is grounded on a difference in meaning. The Ambiguity Theory holds while the Implicature Theory denies that definite descriptions are

\footnotetext{
* Department of Philosophy

University of Genoa

Via Balbi, 5 16126, Genoa, Italy

e-mail:maxi@nous.unige.it

**This work is supported by the program POSDRU/89/1.5/S/63663.
} 
ambiguous expressions, having an attributive meaning and a referential meaning.

Contextualists like Recanati (1989, 1993) and Bezuidenhout (1997) have attempted to steer between the Ambiguity Theory and the Implicature Theory. Contextualists subscribe to Grice's Modified Occam Razor: senses are not to be multiplied beyond necessity. However they deny that conformity to Grice's principle implies that it is not possible for a (non-indexical) sentence to express different propositions in different contexts. Recanati distinguishes three levels to be considered: (i) the level of the linguistic meaning, (ii) the level of the proposition expressed (what is said, the intuitive truth-conditional content), (iii) the level of the proposition communicated. Ambiguity is located at the first level of Recanati's tripartite distinction and contextualists hold that the difference between attributive and referential interpretations of definite descriptions resides in a difference at the second level of the proposition expressed without rooting that difference in a genuine ambiguity. There are two tenets of the Contextualist Theory:

1. A definite description "the F" has a unitary meaning. There is one and only one convention of language governing the use of "the F".

2. A sentence in which the definite description "the F" occurs is contextsensitive and can be uttered to express an object-dependent proposition or an object-independent proposition depending on the context of utterance.

I claim that the early contextualist account provided by Recanati and Bezuidehnout based on the idea that definite descriptions are semantically underdetermined and in need of a completion from the contextually available information through an optional top-down pragmatic process suffers from an explanatory gap. In section 2, I expound the explanatory gap in the early versions of the Contextualist Theory provided by Recanati and Bezuidenhout. In section 3, I present an alternative implementation of the Contextualist Theory based on a linguistically driven (bottom-up) process of saturation. In section 4 , I argue that any account of the referential/attributive distinction based on a process of modulation (top-down) is bound to fail. In section 5, I distinguish further the account based on saturation from the account based on modulation and give more evidence in favor of the former.

\section{The explanatory gap of contextualism}

In order to steer successfully between the Ambiguity Theory and the Implicature Theory, the Contextualist Theory needs to be substantiated by an account of the unitary meaning of definite descriptions that explains how a 
Lodz Papers in Pragmatics 7.2 (2011)/Special Issue on Context and Contextualism: 291-307 DOI: $10.2478 / \mathrm{v} 10016-011-0016-3$

description like "the F" might contribute an object to the proposition expressed in one context and a descriptive content to the proposition expressed in another context. We need an account of the manner in which the proposition expressed at the second level depends on the unitary meaning at the first level plus the context of utterance. This is an explanatory gap that the Contextualist Theory must bridge:

The explanatory gap: how can the unitary meaning at the first level generate truthconditional contents that diverge in type - object-dependent/object-independent - at the second level?

I am in disagreement with Recanati and Bezuidenhout on the early account they provide to bridge the explanatory gap. The point of disagreement is brought up considering Neale's (1990: 110-112) objection to Recanati's version of the Contextualist Theory. Neale maintains that if an expression is unambiguous, then language conventions assign a unitary meaning to it. And if an expression has a unitary meaning, then the propositions expressed in different contexts by its utterances are of the same type. For example, Neale says, $I$ is unambiguous because it always refers to the speaker of the context of utterance. The utterance of I am $G$ always expresses an object-dependent proposition. Likewise that is unambiguous because it always refers to the object of the speaker's demonstration and that is $G$ always expresses an object-dependent proposition. The only examples of unambiguous context-sensitive expressions are indexicals and indexical utterances always express propositions of the object-dependent type. There is no shift in type of proposition from one context to another.

Recanati (1989) replied that this objection is question begging against the Contextualist Theory since it assumes that (i) the logical form of the sentence uttered and consequently the type of the proposition expressed cannot be contextdependent and (ii) all forms of context-sensitiveness are to be reduced to indexicality. However Recanati's reply, as Recanati acknowledges, stands only if the Contextualist Theory is implemented with an account of the unitary meaning in virtue of which definite descriptions make different contributions to the propositions expressed. A full answer to Neale's objection must combine two aspects:

(1) Unity of meaning.

(2) Variation in type of propositions expressed.

I claim that the contextualist solution leaves the explanatory gap open because it does not provide a satisfactory combination of (1) with (2). Unity of meaning requires that meaning performs the same function in all contexts of utterance. But how can meaning deliver truth-conditional contents that diverge in type - objects in the referential uses and descriptive contents in the attributive uses - and, being 
unitary, perform the same function in all contexts of utterance? Compare Recanati's view on definite descriptions with his view on indexicals. Recanati holds that indexicals have two semantic features: (i) a descriptive content (like "the speaker of the utterance" for "I") and (ii) a referential convention (REF). ${ }^{1}$ REF triggers the psychological process of synecdochic transfer in order (i) to search among the de re modes of presentations the one which contains the descriptive content of the indexical as a part and (ii) to select the object of that mode of presentation as the truth-conditional content of the indexical. This is to say that indexicals are marked to be referential expressions by REF.

Recanati's view on definite descriptions is different. Recanati says that definite descriptions have a descriptive content, but their meaning contains neither an instruction like REF nor an instruction like NONREF - which is the instruction to use definite descriptions to always express object-independent propositions.

The problem, then, is to say what is the function of the unitary meaning of definite descriptions that remains constant through different contexts of utterance and how it contributes to generate truth-conditional contents that diverge in type. Recanati's and Bezuidenhout's answer is that definite descriptions have a constant descriptive content: "the F" has the descriptive content [the $\mathrm{x}$ : $\mathrm{Fx}]^{2}$ and that the context decides whether such descriptive content is to be used to express an objectdependent proposition or an object-independent proposition. What is not clear with this answer is whether and to what extent it is different from the Ambiguity Theory.

Recanati (1989: 235) says that the meaning of a sentence partly consists in indications concerning the conditions under which an utterance of the sentence expresses a true proposition. These conditions are not the truth-conditions of the utterance, rather the conditions which must be satisfied in a world $w$ for any utterance of the sentence in $w$ to express a true proposition in $w$. The meaning of a subsentential expression is its contribution to such conditions. For example, the conditions under which an utterance of I am French expresses a true proposition is that the speaker of the utterance is French and the meaning of $I$ is the indication that there exists the speaker of the utterance. Likewise, the meaning of "the $F$ is $\mathrm{G}$ " tells us that any utterance of it expresses a true proposition only if there is an $\mathrm{x}$ such that $\mathrm{x}$ is uniquely $\mathrm{F}$ and $\mathrm{x}$ is $\mathrm{G}$. Definite descriptions have unitary meanings that help fix the conditions under which the utterances of the sentences in which they occur express true propositions on the model of the descriptive content associated to the character of indexicals.

\footnotetext{
${ }^{1}$ Bezuidenhout (1997) defends a different view. She holds that not even indexicals are marked with REF. However, my criticism stands because she does not explain how the unitary meanings of indexicals and definite descriptions perform the same function in all contexts of utterance and yet deliver truth-conditional contents that diverge in type.

${ }^{2}$ I follow Neale's (1990) view that treats definite descriptions as restricted quantifiers and his notation.
} 
Lodz Papers in Pragmatics 7.2 (2011)/Special Issue on Context and Contextualism: 291-307 DOI: $10.2478 / \mathrm{v} 10016-011-0016-3$

The difficulty with this view is that to assign definite descriptions descriptive contents is not enough to explain how their unitary meaning contributes to the determination of their truth-conditional contents. With respect to indexicals the assignment of descriptive contents is accompanied by the instruction contained in REF to make reference to objects. If the assignment of descriptive contents to definite descriptions is not accompanied by any instruction as to what to do with such descriptive contents, one does not get an explanation of the role of the meaning of definite descriptions in the determination of their truth-conditional content. The meaning of "the F" does not tell us whether the condition that there is an $\mathrm{x}$ such that $\mathrm{x}$ is uniquely $\mathrm{F}$ is a contextual condition for the utterance of any sentence containing it to be true or a truth-condition proper. ${ }^{3}$ To say that definite descriptions have a descriptive meaning and pragmatic processes working on contextually available information decide whether it is used for fixing a contextual condition or a contribution the truth-conditions proper is not enough to make a genuine alternative to the Ambiguity Theory. After all, disambiguation too is a pragmatic process working on contextually available information.

The view that definite descriptions have a descriptive content and the context of utterance decides whether to use it referentially or attributively is no more illuminating than saying that definite descriptions have a descriptive content and the context of utterance decides whether to use it in combination to REF or in combination to NONREF. This view is a notational variant of the view that definite descriptions have two meanings, the referential one and the attributive one. The referential meaning of a definite description like "the $F$ " is given by [the $\mathrm{x}$ : Fx] + REF and the attributive meaning is given by [the $\mathrm{x}$ : Fx] + NONREF. The explanatory gap, i.e. the need for an explanation of how the unitary meaning can deliver truth-conditional contents that diverge in type, remains unanswered from within the contextualist perspective. The contextualist solution collapses into the Ambiguity Theory since the intervention of the context to decide to use a definite description referentially or attributively reduces to a process of disambiguation between [the $\mathrm{x}: \mathrm{Fx}]+\mathrm{REF}$ and [the $\mathrm{x}: \mathrm{Fx}]+\mathrm{NONREF}$.

\footnotetext{
${ }^{3}$ Bezuidenhout holds more or less the same view as Recanati's. She says that whether the descriptive content is used in an identifying way (attributively) or in a criterial way (referentially) must be recovered on the basis of considerations of relevance and contextually available information about the speaker's directive intentions. The point is that disambiguation too is a matter of recovering the speaker's directive intentions from contextually available information.
} 


\section{The Two-Stages Theory}

The account I propose to bridge the explanatory gap in the Contextualist Theory consists in thinking of the process that leads from the context of utterance to the truth-conditional content of a definite description as a two-stages process. ${ }^{4}$ At the first stage the meaning determines the pointer. At the second stage a contextually determined function takes the pointer as argument and yields the truth-conditional content as value.

Stage 1: Linguistic meaning $\rightarrow$ pointer.

Stage 2: Contextually determined function + pointer $\rightarrow$ truth-conditional content.

The truth-conditional content might be the pointer itself, or an enrichment of it, or a particular object that satisfies or is believed to satisfy it within a restricted domain or satisfies or is believed to satisfy an enrichment of it within a restricted domain. Consider the following utterance in the course of a conversation about the presidency of the USA:

(A) The president is tall.

The linguistic meaning of the definite description the president determines the following descriptive content as pointer:

[the $\mathrm{x}$ : President $\mathrm{x}$ ]

Such descriptive content is given as argument to a contextually determined function that yields the truth-conditional content. (A) allows for an attributive interpretation like (1) and for a referential interpretation like (2).

(1) [the $\mathrm{x}$ : President of the USA in $2011 \mathrm{x}$ ](tall $\mathrm{x})$.

(2) Barack Obama is tall.

In (1) the descriptive content [the $\mathrm{x}$ : President $\mathrm{x}$ ] is given as argument to a function

\footnotetext{
${ }^{4}$ I borrow the idea of the two-stages process from Nunberg (1993). Nunberg applies the two-stages process to the semantic interpretation of indexicals and argues against the view that indexical utterances always express object-dependent propositions. Nunberg (2004) revises his former theory and explains the descriptive interpretations of indexicals and demonstratives as the very things that their linguistic meanings pick out of the context provided a certain standard of granularization of the context.
} 
Lodz Papers in Pragmatics 7.2 (2011)/Special Issue on Context and Contextualism: 291-307 DOI: $10.2478 / \mathrm{v} 10016-011-0016-3$

that yields an enrichment of it: [the x: President of the USA in $2011 \mathrm{x}$ ]. In (2) the same descriptive content is given as argument to a function that yields the individual that satisfies the enrichment of the descriptive content in the actual world. It might happen that the truth-conditional content and the pointer of a definite description coincide. Consider the following example:

(B) The president of the USA in 2011 is tall.

(B) allows for an attributive interpretation:

(3) [the $\mathrm{x}$ : President of the USA in $2011 \mathrm{x}$ ](tall $\mathrm{x})$.

In (3) the descriptive content of the definite description [the $\mathrm{x}$ : President of the USA in $2011 \mathrm{x}$ ] is given as argument to the identity function that returns the same descriptive content as value.

In general, the function from the context of utterance to the truth-conditional content of a definite description is a composite function, only part of which consists in the determination of the pointer by the linguistic meaning. The rest of the function depends on the contextual information broadly intended, i.e. speakers' intentions, beliefs, presuppositions, linguistic context, etc. The cases in which the truth-conditional content and the pointer of the utterance of a definite description coincide are explained by the fact that in such cases the context selects the identity function to determine the truth-conditional content. Even if it happens that the truth-conditional content and the pointer coincide, that circumstance does not constitute a linguistic kind. In those cases too, the pointer is always determined by the linguistic meaning, whereas the truth-conditional content is always the value of a contextually determined function that takes the pointer as argument. As a matter of fact, in those cases the context selects the identity function.

I call this account of the referential/attributive distinction "The Two-Stages Theory" (TST). TST offers a better implementation of the Contextual Theory because it bridges the explanatory gap. It combines the claim that definite descriptions have a unitary meaning that plays the same function in all contexts of utterance - the determination of the pointer - with the claim that the type of the propositions expressed varies according to the contexts of utterance. TST avoids the thread of collapsing into the Ambiguity Theory. Definite descriptions have a unitary meaning and linguistic competence consists in the ability (i) to exploit such meaning to determine the pointers and (ii) to exploit the pointers together with contextually selected functions to determine the truth-conditional contents. The meaning of definite descriptions operates at a subcompositional level. Given a definite description "the F", its linguistic meaning yields a subcompositional representation: 
$\langle[$ the $\mathrm{x}: \mathrm{Fx}] ; f\rangle$

which consists of a pair formed of the descriptive content of the definite description - the pointer - and a functional variable. Contextual information provides the value of the functional variable, which is a function from the pointer to the truth-conditional content that might vary in type as the context of utterance changes.

According to this view, and contrary to Recanati's, there are no optional primary (i.e. concerning what is said) pragmatic processes in the determination of the truth-conditional content of definite descriptions. The assignment of a value to the functional variable $f$ is mandatory as required by the subcompositional representation delivered by the linguistic meaning. In this sense, the process that leads to the referential or attributive interpretation is linguistically driven as based on a process of saturation. The context sensitiveness of definite descriptions is marked by the functional variable $f$ in the subcompositional representation delivered by the linguistic meaning. Insofar as the process leading to the referential or attributive interpretation is linguistically driven it is not a process of disambiguation. We deal with a unitary meaning playing a unique role in the process of the determination of truth-conditional contents, which might nonetheless diverge in type.

In the next two sections I will address and answer two objections. The first objection is about my claim that the early versions of the Contextualist Theory collapse into the Ambiguity Theory. It might be objected that my claim is not sufficiently argued, as in light of Recanati's more recent works $(2004,2010)$ the process leading to the referential or attributive interpretation of definite descriptions might be thought of as a process of modulation and not as a process of disambiguation.

The second objection concerns the extent to which my view really differs from the theories I criticize since in Recanati's pragmatic account (2010) one can pair every expression susceptible to modulation with a variable standing for a modulation function provided by the context and there might be cases of "zero modulation" in which the value of the variable is the identity function.

\section{Referential interpretations and modulation}

My charge that the early versions of the Contextualist Theory collapse into the Ambiguity Theory is conditional. If one limits himself to saying that definite descriptions have a descriptive meaning and pragmatic processes decide whether to use it referentially or attributively, i.e. as a contextual condition or as a truthcondition proper, then one does not say enough to distance his theory from the 
Lodz Papers in Pragmatics 7.2 (2011)/Special Issue on Context and Contextualism: 291-307 DOI: $10.2478 / \mathrm{v} 10016-011-0016-3$

Ambiguity Theory.

I agree that matters are different if one tries to refine the Contextualist view through the notion of modulation which Recanati has largely expounded in his works. Modulation is defined as an optional (top-down) pragmatic process affecting the intuitive truth-conditional content of utterances through which the meaning $\mathrm{m}$ of an expression is mapped to a distinct meaning $\mathrm{g}(\mathrm{m})$ where " $\mathrm{g}$ " is a contextually defined function. Recanati recognizes three basic kinds of modulation processes: (i) free enrichment, (ii) loosening and (iii) semantic transfer. Free enrichment restricts and loosening broadens the conditions of application of an expression and semantic transfer maps the content of an expression to another content bearing a systematic relation to it.

I claim that modulation alone is not sufficient to explain the referential interpretations of definite descriptions. The point that remains to be explained is how modulation can change the type of the semantic values of definite descriptions and make them express object-dependent or object-independent propositions according to the context. Free enrichment and loosening can turn an incomplete definite description into a complete one, or a definite description without denotation into a denoting one by restricting or broadening the condition of application of the descriptive part of the definite description. For example, the incomplete description the table can be turned into the complete one the table in room 401, and the non-denoting description the ATM that swallowed my credit card can be turned into a denoting one by relaxing the conditions of application of swallow. ${ }^{5}$ But free enrichment and loosening do not explain how descriptions can turn their semantic status from denoting to referring expressions. Likewise, the cases of semantic transfer Recanati discusses are all cases in which a property is mapped to another property like the mapping of being parked there to being the owner (or driver) of a car parked there or being a ham sandwich to being a ham sandwich orderer or being a lion to being a statue representing a lion. Therefore semantic transfer explains how the content of, say, the definite description the ham sandwich is mapped to the content of the definite description the ham sandwich orderer but does not explain the referential interpretation of the modulated description. The explanatory gap as to how the utterance of a sentence containing a definite description might express an object-dependent proposition is unanswered.

It is true that one can complete a definite description through modulation so as to make the proposition expressed by a sentence containing that description equivalent to an object-dependent proposition. Given a definite description "the F", its content can be mapped to the descriptive content [the $\mathrm{x}$ : Fx and $\mathrm{x}=\mathrm{a}$ ], where "a" is a referring term, i.e. to what Neale calls a Gödelian completion. Accordingly, the proposition expressed by the sentence "the $F$ is $G$ " becomes equivalent to the

\footnotetext{
${ }^{5}$ There can be no real swallowing on the part of an ATM. See Recanati ( 2004: 26).
} 
300

\author{
Massimiliano Vignolo \\ Contextualism, Pragmatics and Definite Descriptions
}

object-dependent proposition expressed by the sentence Fa and Ga.

I think that this strategy for accounting for the referential interpretations of definite descriptions is bound to fail. My objection to it is that it delivers truthconditional results that do not correspond to the intuitive truth-conditional contents Recanati wants to account for. Consider the utterance of the sentence "the $F$ is G" where "the F" is a misdescription of the object referred to and suppose the object referred to is a $\mathrm{G}$. The intuitive truth-conditional content of the utterance is true since the object referred to is a G. However, replacing the definite description with a Gödelian completion yields a false proposition. The proposition so expressed is false because the object referred to is not an F.. It might be observed that in my objection I am assuming that misdescriptions too can be used to make reference. My assumption might be put in question but I think it cannot be rejected by a contextualist who works with the same notion of intuitive truth-conditional content as Recanati's. Consider the example of the utterance of her husband is kind to her where her husband is used to refer to a man who is not the husband of that woman. It is agreed that there is a proposition communicated about that man saying of him that he is kind to that woman. But a contextualist who endorses Recanati's view cannot say that nothing is said due to a failure of reference and that the proposition communicated is the result of a Gricean implicature, otherwise he ought to explain why, contrary to the principle of theoretical parsimony, the same Gricean machinery cannot be at work in cases of descriptions whose descriptive content applies to the objects referred to. A contextualist must admit that the proposition communicated saying that that man is kind to that woman is the proposition expressed corresponding to the intuitive truth-conditional content and therefore that misdescriptions can be used to make reference.

One might try to refine the above proposal and suggest applying the pragmatic process of loosening to the satisfaction condition of the predicate " $F$ " so as to make it apply to the object referred to and overcome the difficulty raised by misdescriptions. But even this suggestion must be resisted. The point is that the Gödelian completion of "the F" adds always the satisfaction conditions of " $F$ " to the truth-conditional content, no matter how loose the satisfaction conditions of "F" have been modulated. Yet such satisfaction conditions are never part of the intuitive truth-conditional content of the utterance of a sentence containing the definite description "the $F$ " in the referential interpretation.

In the spirit of Recanati's modulation there is still a move that one might try to make. One might consider the process of synecdochic transfer and hold that in cases of referential interpretations of definite descriptions the process of synecdochic transfer is at work. As noted above, synecdochic transfer is the process through which the linguistic meaning of indexicals is mapped to their semantic values. The move under consideration would be to equate referential definite descriptions to indexicals. I think this suggestion too is mistaken. 
Lodz Papers in Pragmatics 7.2 (2011)/Special Issue on Context and Contextualism: 291-307 DOI: $10.2478 / \mathrm{v} 10016-011-0016-3$

My claim is that referential definite descriptions and indexicals are semantically different and any adequate Contextualist Theory need recognize and explain such semantic difference. The semantic feature that distinguishes definite descriptions from indexicals is that the descriptive content of a definite description has a semantic role even when the description is used referentially. The descriptive content is part of what is said, though its role does not affect the truth-conditions of what is said. The evidence for this claim emerges from the consideration that what is said is the input for processing implicatures. Consider the following example: ${ }^{6}$

(4) The notoriously moody tennis player insulted the referee on court today.

Suppose (4) is uttered by a sport reporter commenting on John McEnroe's behavior on court during his last game. In that scenario, the referential interpretation of the definite description the notoriously moody tennis player is highly suggested. The speaker wanted to make reference to John McEnroe. Plainly, had his communicative intention been simply to refer to John McEnroe and to say of him that he insulted the referee, he could have uttered the proper name John McEnroe or the definite description the last year Wimbledon champion with the same confidence of success. However, although other expressions could have ensured reference to John McEnroe and the expression of the proposition that John McEnroe insulted the referee, those expressions could not have served the purpose of alluding to the fact that John McEnroe behaved inappropriately on court in many previous occasions. The allusion to John McEnroe's previous misbehavior on court might be intended to communicate the speaker's disapproval of John McEnroe's bad temper, or his desire that the regulation of the international tennis game federation be strengthened to the point of preventing tennis players from misbehaving in such a rude way on court.

There are implicatures that are easily suggested by the utterance of the definite description the notoriously moody tennis player that are not so easily suggested by the utterance of the proper name John McEnroe or other definite descriptions like the last year Wimbledon champion. The speaker then chose to refer to John McEnroe by the utterance of the definite description the notoriously moody tennis player for a precise communicative intention.

The descriptive content of a referential definite description does not serve merely to enable the hearer to pick out the object the speaker intends to refer to. The descriptive content contributes to what is said as the input for processing implicatures, which includes more than the truth-conditional content. Definite descriptions encode conceptual representations in virtue of their descriptive content that give access to background assumptions and knowledge that are relevant for

\footnotetext{
${ }^{6}$ I borrow this example from Rouchota (1992).
} 
inferring implicatures and this function goes beyond that of encoding instructions as to how to identify a referent.

That definite descriptions are expressions we use to induce implicatures is an essential feature that marks a semantic regularity in their usage and distinguishes them from indexicals. Any theory that equates the usage of referential definite descriptions to the usage of indexicals misses the point of explaining one semantic characteristic of referential definite descriptions that makes them different from indexicals.

TST allows us to think of the semantic content of definite descriptions as not exhausted by their truth-conditional content. Although the pointer constitutes a subcompositional component that does not enter the truth-conditional content, it plays an important semantic role that is essential to capture what is said by the utterance of a definite description, if we accept that what is said is the input for processing implicatures. TST offers an explanation of the regularity that marks the usage of definite descriptions for prompting conversational implicatures by stating that the semantic interpretation of definite descriptions is a two-stages process that computes the descriptive content as pointer first and then the truth-conditional content.

More evidence that referential definite descriptions and indexicals - and demonstratives - possess a different semantics is provided by Nunberg's (2004: 265-267) considerations on descriptive uses of indexicals and demonstratives. Consider the utterance of the following sentence on the First of November 2011:

(5) Today is always the biggest party day of the year.

In (5) only a descriptive interpretation is admissible ${ }^{7}$ according to which the indexical Today does not refer to the day of the utterance but to a property instantiated by it, say the property of being the first Monday of November. Suppose that the First of November 2011 is Sophie's eleventh birthday. If referential definite description behaved like indexicals, then we ought to expect that the utterance of the following sentence is susceptible to the same descriptive interpretation:

(6) Sophie's eleventh birthday is always the biggest party day of the year.

Yet (6) is not susceptible to a descriptive interpretation. To make the point even more vivid, consider the utterance of the following sentence on the First of November 2011:

\footnotetext{
${ }^{7}$ Due to the presence of always in the sentence.
} 
Lodz Papers in Pragmatics 7.2 (2011)/Special Issue on Context and Contextualism: 291-307 DOI: $10.2478 / \mathrm{v} 10016-011-0016-3$

(7) The day of this utterance is always the biggest party day of the year.

If one and the same process of synecdochic transfer were at work in the interpretation of Today in (5) and of the day of this utterance in (7) we ought to expect that the descriptive interpretation is admissible in (7) too, given that the descriptive meaning of Today is the same as the descriptive meaning of the day of this utterance. Yet the descriptive interpretation is not allowed in (7). The invited conclusion is that referential definite descriptions do not behave semantically as indexicals and demonstratives. Referential definite descriptions are linguistically marked with a feature that prevents descriptive interpretations because their descriptive meaning is always implicit in their semantics. TST explains this semantic feature of definite descriptions saying that the descriptive content of definite description is always part of what is said though in referential uses it is not truth-conditionally relevant. By contrast, explaining referential uses by appealing to the process of synecdochic transfer does not capture this important semantic feature of definite descriptions.

\section{TST and linguistic data}

The second objection concerns the extent to which my theory is a genuine alternative to Recanati's theory. In Truth-Conditional Pragmatics (Recanati 2010) Recanati introduces the function mod taking as argument an expression $\mathrm{E}$ and the context $\mathrm{C}$ in which it occurs. The value of mod is the particular modulation function $\mathrm{g}$ that is relevant for the interpretation of $\mathrm{E}$ in $\mathrm{C}$. If no modulation is contextually appropriate and the expression receives its literal interpretation the value of mod is the identity function.

I have already expounded the reasons why I think modulation does not explain the referential interpretations of definite descriptions, not even if one adds the process of synecdochic transfer to free enrichment, loosening and semantic transfer. The major flaw I detect in the explanation of referential interpretations through modulation is that it does not account for the implicature potential of definite descriptions and for the fact that definite descriptions behave differently from indexicals and demonstratives as they are never susceptible to descriptive interpretations. This is to say that the descriptive content of a definite description cannot be detached from what is said even when it is not part of the truthconditional content, i.e. under a referential interpretation. This is a regular aspect of the usage of definite descriptions and, as such, calls for a semantic explanation, an explanation having to do with linguistic conventions and not for a pragmatic explanation. TST captures this conventional aspect of the usage of definite descriptions by stating that their interpretation is always the result of a two-stages 
process with a mandatory assignment of a contextually determined function. In this respect TST is different from Recanati's theory.

In addition, I think that invoking the modulation process in the version of it that Recanati (2010) employs to argue in favor of truth-conditional pragmatics betrays the nature of Contextualism and opens the way to an objection that Devitt has raised to any pragmatic explanation of referential interpretations of definite descriptions. Devitt (2007a: 19) claims that if the referential uses were not a matter of semantic convention and were explained through pragmatic processes, then it would have been the case that historically the attributive meaning of definite descriptions came before their referential meaning. Indeed, the attributive meaning would feature in the pragmatic explanation of referential uses. The fact is that there is no firm evidence that attributive uses preceded referential ones. Perhaps both uses arose together. And this speaks against the pragmatic view. Bach (2007) has objected that Devitt's criticism rests on a mistaken equation of the attributive interpretation with the quantificational meaning of definite descriptions. Devitt (2007b) has replied, correctly in my view, that to the extent that any pragmatic explanation accords a sort of explicative priority to the quantificational meaning, then it is committed to the attributive interpretations being more fundamental than the referential ones, because the quantificational meaning must have been established and sustained by the regular attributive uses of definite descriptions.

The same objection can be turned against any theory explaining referential interpretations through the notion of pragmatic modulation that Recanati presents in Truth-Conditional Pragmatics. Since every definite description can be used as a complete description in the attributive interpretation ${ }^{8}$ where no modulation is requested, it follows that (i) definite descriptions possess a literal meaning and (ii) the literal meaning of definite descriptions is given by their quantificational meaning. The point is to explain where the literal meanings of definite descriptions come from. As Devitt (2007b: 52) says: "meanings are not God given, they are created by use". Therefore attributive uses must have established the literal quantificational meaning of definite descriptions. Yet there is no evidence that attributive uses preceded referential ones.

By contrasts, TST can predict that attributive uses and referential ones arose together. It is true that the quantificational meaning of definite descriptions is always processed. But it is processed to yield the subcompositional representation that generates an attributive or a referential truth-conditional content only when the functional variable is given a value according to the context of utterance. There is no priority of explanation of attributive uses over referential uses.

\footnotetext{
${ }^{8}$ Of course, many of the descriptions so used will not be complete or denoting, but this is not a semantic point. The point is that every definite description can be used attributively with "zero modulation".
} 
Lodz Papers in Pragmatics 7.2 (2011)/Special Issue on Context and Contextualism: 291-307 DOI: $10.2478 / \mathrm{v} 10016-011-0016-3$

Linguistic data offer more evidence in favor of TST. TST offers an account that accommodates two data that pull our intuitions in two opposite directions. The first datum is employed by Devitt $(2004,2007$ a) to support the Ambiguity Theory. Devitt holds that an important basis for supporting the Ambiguity Theory is the fact that speakers use regularly definite descriptions to express object-dependent propositions without the special stage settings that enable the hearers to calculate the implicatures that are necessary to understand that an object-dependent proposition has been communicated. According to Devitt, this regularity is strong evidence that there is a semantic convention of using definite descriptions to express object-dependent propositions. The fact is not that speakers can use definite descriptions to communicate object-dependent propositions. The fact is that speakers regularly do so. When definite descriptions are used referentially very often other referring expressions are available that speakers could have used to achieve the same referential task, say proper names, demonstratives and complex demonstratives. There is wide consensus that those expressions are genuinely referential, i.e. they are marked as referential by the conventions of the language. If this is true, and if the referential uses of definite descriptions did not issue from a semantic convention then we would expect referential uses of definite descriptions to be very rare whenever those other expressions that are genuinely referential are available to speakers. Yet, as Devitt (2007a: 20) points out, referential uses of definite descriptions are far from rare.

The other datum, instead, is employed by Bach (2007) to oppose the Ambiguity Theory. Bach points out that the thesis that definite descriptions are semantically governed by a referential convention and by an attributive convention contrasts with the fact that there are no languages with two different definite articles, having one, the referential meaning, and the other, the attributive meaning. Hence, the Ambiguity Theory implies the existence of a massive cross-linguistic coincidence, which is highly counterintuitive.

TST accommodates these contrasting data. There is a convention to use definite descriptions with referential or attributive contents depending on the context of utterance, but the definite article is not ambiguous and there is no need to invoke a massive cross-linguistic coincidence. It must be noted that the pragmatic account does not say that there is a convention to use definite descriptions with referential or attributive contents depending on the context of utterance since the referential or attributive interpretations are not the results of a bottom-up, linguistically driven process of saturation. TST fits these linguistic data better than any pragmatic account based on modulation and top-down pragmatic processes.

There is still more evidence in favor of TST. TST gives a straightforward explanation of the overall usage of definite descriptions. Plainly, in referential uses the quantificational meaning of definite descriptions is rarely deployed to uniquely identify the referents. Very often definite descriptions are used to refer to objects 
that are not uniquely identified by the descriptive content either because the descriptive content does not identify anything (more than one object satisfy it), or because the speaker is wrong in believing that the referent satisfies it, or because the speaker believes the hearer wrongly believes that the referent satisfies it, or because the speaker believes the hearer believes the speaker wrongly believes the referent satisfies it. TST explains all these different types of referential uses. ${ }^{9}$ The quantificational meaning is processed to deliver the subcompositional representation. The contextual function maps the descriptive content onto an object that the speaker believes to satisfy it - or an enrichment of it - or that the speaker believes the hearer believes to satisfy it - or an enrichment of it - or that the speaker believes the hearer believes the speaker believes to satisfy it - or an enrichment of it. TST does not require that the object referred to by an utterance of "the F" be an F. It is sufficient that the speaker - or the hearer - believes that it is an F.

With regard to this aspect, too, TST is superior to any pragmatic account of the referential interpretations that makes the descriptive content of descriptions play a contextual role similar to the role of the character of indexicals through the process of synecdochic transfer. ${ }^{10}$ An indexical expression cannot be applied to an object that does not satisfy its character. An utterance of $I$ to refer to the addressee denotes a lack of linguistic competence on the part of the speaker. On the contrary, definite descriptions can be uttered to refer to objects that do not satisfy their descriptive content. An utterance of "the man drinking martini" to refer to the man holding a glass of water does not denote any lack of linguistic competence on the part of the speaker.

\section{References}

Bach, Kent. 2007. Referentially used descriptions: A reply to Devitt. European Journal of Analytic Philosophy 3: 33-48.

Bezuidenhout, Anne. 1997. Pragmatics, semantic underdetermination and the referential/ attributive distinction. Mind 106: 375-409.

Devitt, Michael. 2004. The case for referential descriptions. In: Marga Reimer and Anne Bezuidenhout (eds.). Descriptions and Beyond. Oxford: Clarendon Press, 280-305.

\footnotetext{
${ }^{9}$ Consider the example of the speaker who knows that the man sitting on the throne is a usurper but all his followers believe he is the king. If the speaker wants to say that that man is in the counting house he can utter: The king is in the counting house.

${ }^{10}$ As noted, this is the view Recanati $(1989,1993)$ holds in his early works. Bezuidehout (1997) holds the same view.
} 
Lodz Papers in Pragmatics 7.2 (2011)/Special Issue on Context and Contextualism: 291-307 DOI: $10.2478 / \mathrm{v} 10016-011-0016-3$

- 2007a. Referential descriptions and conversational implicatures. European Journal of Analytic Philosophy 3: 7-32.

—. 2007b. Referential descriptions: A note on Bach. European Journal of Analytic Philosophy 3: 49-53.

Neale, Stephen. 1990. Descriptions. Cambridge, MA: MIT Press.

Nunberg, Geoffrey. 1993. Indexicality and deixis. Linguistics and Philosophy 16: $1-43$.

- 2004. Descriptive indexicals and indexical descriptions. In: Marga Reimer and Anne Bezuidenhout (eds.). Descriptions and Beyond. Oxford: Clarendon Press, 261-279

Recanati, Francois. 1989. Referential/attributive: a contextual proposal. Philosophical Studies 56: 217-249.

—. 1993. Direct Reference. Oxford: Basil Blackwell.

-. 2004. Literal Meaning. New York: Cambridge University Press.

- 2010. Truth-Conditional Pragmatics. Oxford: Clarendon Press.

Rouchota, Villy. 1992. On the referential/attributive distinction. Lingua 87: 137167.

\begin{abstract}
About the Author
Massimiliano Vignolo has a postdoctoral fellowship at the University of Genova. After taking his Diplôme d'Études Supérieures at the University of Genève under the supervision of Prof. Kevin Mulligan, and his PhD at the University of Eastern Piedmont under the supervision of Prof. Diego Marconi, he studied under Prof. John Perry at the University of Stanford. He is the author of Afferrare Pensieri (2001), Use against Scepticism (2009) and the co-editor (with Michael Beaney and Carlo Penco) of Explaining the Mental (2007). He is the author of several papers in philosophy of language, philosophy of mind and metaphysics published in international philosophical journals. [see: http://www.dif.unige.it/epi/hp/vignolo/]
\end{abstract}

